\title{
Effects of Dibutyryl Cyclic AMP on Contractile Performance of Isolated Heart Muscle Depressed by Thiamylal and Halothane
}

\author{
Naofumi Iwatsuki and Kenichi Iwatsuki \\ Department of Anesthesiology, Tohoku University School of \\ Medicine, Sendai
}

\begin{abstract}
Iwatsuki, N. and Iwatsuki, K. Effects of Dibutyryl Cyclic AMP on Contractile Performance of Isolated Heart Muscle Depressed by Thiamylal and Halothane. Tohoku J. exp. Med., 1974, 113 (4), 357-363 — Effects of dibutyryl cyclic AMP (D-cAMP) on contractile performance of isolated dog heart muscle were investigated with special reference to its effectiveness for the reversal of myocardial depression produced by sodium thiamylal and halothane. D-cAMP increased the velocity of shortening at $0.4 \mathrm{~g}$ preload ( $V^{\prime} \max$ ) and isometric force dose-dependently at concentrations over $1 \times 10^{-3} \mathrm{M}$ and net-shortening over $2 \times$ $10^{-3} \mathrm{M}$. However, the time course of its action was slow, with the peak effect about $70 \mathrm{~min}$ after the administration of the drug. This was a sharp contrast to a very rapid onset of action of epinephrine. When $V^{\prime} \max$ was depressed to about $75 \%$ of the control by $3.3 \mathrm{mg} \%$ of thiamylal or $7.1 \mathrm{mg} \%$ of halothane, $3 \times 10^{-8} \mathrm{M}$ of D-cAMP counteracted the depression produced by thiamylal and V'max was increased to $160 \%$ of the control, but it failed to reverse the depression produced by halothane and $V^{\prime} \max$ remained $90 \%$ of the control. When the concentrations of halothane were lower than $5 \mathrm{mg} \%$, however, D-cAMP at this concentration increased V'max more than the control level. The different responses to D-cAMP of the myocardium depressed by thiamylal and halothane suggest that there may be some differences between these two anesthetic agents in the mechanism for depressing myocardial contractility. —— dibutyryl cyclic AMP; isolated heart muscle; inotropism; thiamylal; halothane
\end{abstract}

A positive inotropic effect of catecholamines has been postulated to result from an increase in the intracellular level of cyclic AMP (cAMP). Exogenous cAMP, however, failed to exert a positive inotropic effect, probably because of its inability to pass the cardiac cell membrane (Robinson et al. 1965). Dibutyryl cyclic AMP (D-cAMP), a derivative of cAMP, being more lipid soluble, is thought to pass the cell membrane more easily than cAMP and to resist inactivation by phosphodiesterase (Posternak et al. 1962). Recently Skelton et al. (1970) demonstrated a positive inotropic effect of D-cAMP on isolated cat papillary muscle. Our interest is whether D-cAMP is effective or not for the reversal of myocardial depression produced by anesthetic agents. Therefore, the present study was undertaken to investigate the effectiveness of D-cAMP for the reversal of contractile

Received for publication, July 5, 1974. 


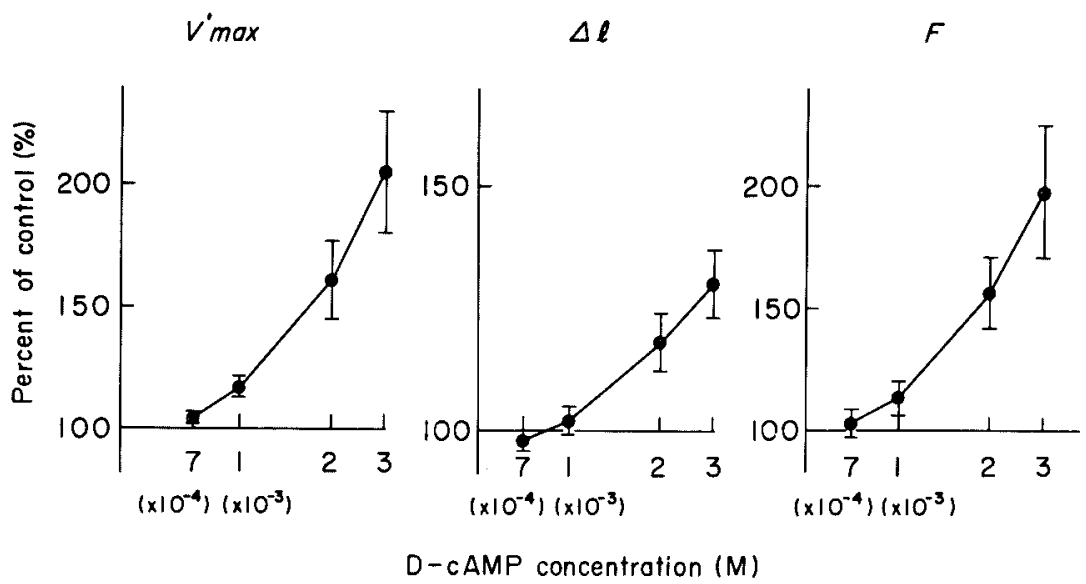

Fig. 1. Relations between the concentrations of D-cAMP and the velocity of shortening at $0.4 \mathrm{~g}$ preload ( $V^{\prime} \max$ ), net-shortening $(\Delta l)$ and isometric force $(F)$. Ordinate, $V^{\prime} \max$, $\Delta l$ and $F$ expressed in percentage of the control; abscissa, concentration of D-cAMP in $M$.

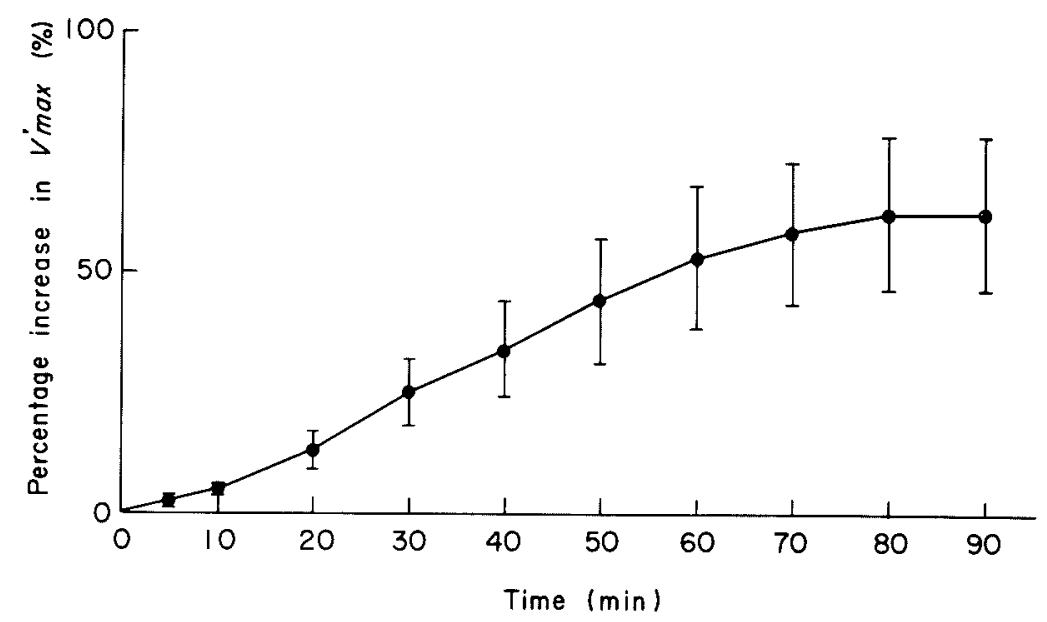

Fig. 2. The time course of an increase in the velocity of shortening at $0.4 \mathrm{~g}$ preload (V'max) produced by $3 \times 10^{-3} \mathrm{M}$ of D-cAMP. Ordinate, percent changes in $V^{\prime} \max$; abscissa, time in min after the administration of D-cAMP.

performance of isolated heart muscle which was depressed by sodium thiamylal and halothane.

\section{Materials and Methods}

Seventeen trabeculae were excised from the right ventricles of normal healthy dogs anesthetized with sodium pentobarbital $(25 \mathrm{mg} / \mathrm{kg}$ intravenously). Muscle length and cross sectional area were $6.04 \pm 0.30 \mathrm{~mm}$ and $1.22 \pm 0.12 \mathrm{~mm}^{2}$ (mean \pm s.t.), respectively.

The trabecula was suspended in Krebs-Henseleit solution which was kept at $27^{\circ} \mathrm{C}$ and bubbled with a $95 \% \mathrm{O}_{2}-5 \% \mathrm{CO}_{2}$ gas mixture. Electrical stimulation was applied at a 


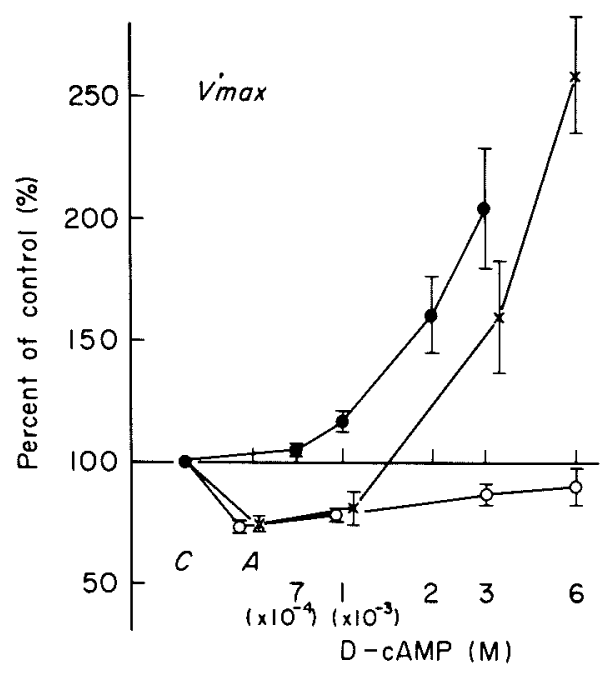

Fig. 3. Relations between the concentrations of D-cAMP and the velocity of shortening at $0.4 \mathrm{~g}$ preload $\left(V^{\prime} \max \right)$ under the influence of thiamylal and halothane. The black circles $(\bullet)$ show $V^{\prime} \max$ produced by D-cAMP without the administration of anesthetic agents. The cross marks $(x)$ and the white circles $(0)$ show $V^{\prime} \max$ produced by $\mathrm{D}$. cAMP under the influence of $3.3 \mathrm{mg} \%$ of thiamylal and $7.1 \mathrm{mg} \%$ of halothane, respectively. $C$ indicates the control and $A$ the administration of anesthetic agents. The numerals on the horizontal axis show the concentrations of D-cAMP expressed in M.

frequency of 18 per minute to the muscle with a square wave of 5 msec duration at a voltage 15-20\% above threshold. The isotonic lever system, muscle bath, electrical stimulator and recording equipment used in this study have already been described in detail in the previous report (Iwatsuki 1973). Sodium thiamylal dissolved in distilled water was added directly to the bathing solution. Halothane was administered by passing its vapor through the bathing solution after vaporized with a Fluotec vaporizer and its concentrations in the solution were measured by gas chromatography. D-cAMP was added to the bathing solution at concentrations from $7 \times 10^{-4} \mathrm{M}$ to $3 \times 10^{-3} \mathrm{M}$ to obtain the concentration-response relations of the velocity of shortening at $0.4 \mathrm{~g}$ preload ( $V^{\prime} \max$ ), net-shortening $(\Delta l)$ and isometric force $(F)$. The time course in the recovery process from the effect of D-cAMP on $V$ 'max was observed by replacing the bathing solution with fresh D-cAMP free solution after the peak effect was obtained at the concentration of $3 \times 10^{-3} \mathrm{M}$ of D-cAMP. The effectiveness of D-cAMP for the reversal of myocardial depression was exmained by observing its effects at various concentrations on V'max which was depressed to a similar degree by 3.3 $\mathrm{mg} \%$ of thiamylal or $5.5-8.6 \mathrm{mg} \%$ (mean $7.1 \pm 0.7 \mathrm{mg} \%$ ) of halothane. D-cAMP $3 \times 10^{-3}$ $M$ was administered also to investigate its effectiveness for the reversal of myocardial depression produced by halothane at various concentrations up to $10 \mathrm{mg} \%$. The measurements were made when each parameter reached a steady state. All values were expressed as mean \pm S.E. and analyzed statistically by the Student's $t$-test.

\section{Results}

\section{Effects of $D$-cAMP on normal heart muscle}

$\mathrm{D}$-cAMP at concentrations over $1 \times 10^{-3} \mathrm{M}$ resulted in a concentrationdependent increase in $F$ and $V^{\prime} \max$. An increase in net-shortening $(\Delta l)$ was 
TABLE 1. Effects of D-cAMP on the velocity of shortening at $0.4 \mathrm{~g}$ preload ( $V^{\prime}$ max), of thiomylal

\begin{tabular}{|c|c|c|c|c|c|c|c|}
\hline \multicolumn{6}{|c|}{ D-cAMP only } & \multicolumn{2}{|c|}{ Thiamylal $3.3 \mathrm{mg} \%$} \\
\hline \multicolumn{2}{|c|}{ D-cAMP } & $7 \times 10^{-4} \mathrm{MI}$ & $1 \times 10^{-3} \mathrm{M}$ & $2 \times 10^{-3} \mathrm{M}$ & $3 \times 10^{-3} \mathrm{M}$ & 0 & $1 \times 10^{-3} \mathrm{M}$ \\
\hline \multirow{3}{*}{$V^{\prime} \max$} & $\%$ & 104.7 & 117.4 & 161.3 & 205.3 & 74.6 & 81.2 \\
\hline & S.E. & \pm 1.6 & \pm 4.0 & \pm 16.0 & \pm 24.6 & \pm 3.0 & \pm 7.3 \\
\hline & $p$ & NS* & $0.05>p^{*}$ & $0.05>p^{*}$ & $0.05>p^{k}$ & $0.01>p^{k}$ & $\mathrm{NS} \dagger$ \\
\hline \multirow{3}{*}{$\Delta l$} & $\%$ & 98.0 & 101.5 & 117.7 & 130.3 & 75.5 & 76.6 \\
\hline & S.E. & \pm 2.2 & \pm 3.1 & \pm 5.8 & \pm 6.7 & \pm 3.0 & \pm 5.4 \\
\hline & $p$ & NS* & NS* & $0.05>p^{*}$ & $0.05>p^{*}$ & $0.01>p^{*}$ & $\mathrm{NS}+$ \\
\hline \multirow{3}{*}{$F$} & $\%$ & 103.0 & 112.8 & 156.4 & 197.3 & 57.4 & 51.9 \\
\hline & S.E. & \pm 6.3 & \pm 7.1 & \pm 15.0 & \pm 27.3 & \pm 1.5 & \pm 4.4 \\
\hline & $p$ & NS* & NS* & $0.05>p^{*}$ & $0.05>p^{k}$ & $0.001>. p^{k}$ & $\mathrm{NS} \dagger$ \\
\hline
\end{tabular}

The values are expressed as mean percentage \pm S.E. of the control.

* compared with the values without D-cAMP and anesthetics.

$\dagger$ compared with the values at zero concentration of D-cAMP under the influence of

observed at concentrations over $2 \times 10^{-3} \mathrm{M}$ (Fig. 1). The time course of an increase in $V^{\prime} \max$ produced by $3 \times 10^{-3} \mathrm{M}$ of $\mathrm{D}$-cAMP is shown in Fig. 2 . $V^{\prime} \max$ increased gradually and reached its peak effect about $70 \mathrm{~min}$ after the administration of the drug. The time course of recovery from its effect was also slow. $V$ 'max began to show a decrement at $33 \pm 4.9 \mathrm{~min}$ and returned to the control level at $95 \pm 5.2 \mathrm{~min}$ on the average after washing out the drug. D-cAMP at high concentration such as $6 \times 10^{-3} \mathrm{M}$ occasionally evoked irregular spontaneous muscle contraction, which was reversed by xylocaine at a concentration of $1.1 \mathrm{mg} / \mathrm{ml}$, but was not by propranolol at concentrations up to $1.5 \mathrm{mg} / \mathrm{ml}$, which was about ten times higher than the ordinary effective dose.

\section{Effects of D-cAMP on heart muscle depressed by thiamylal or halothane}

The administration of $3.3 \mathrm{mg} \%$ of thiamylal depressed $V^{\prime} \max$ to $74.6 \pm 3.0 \%$ of the control. D-cAMP at the concentration of $3 \times 10^{-3} \mathrm{M}$ reversed the depression and increased V'max to $160 \pm 24.3 \%$ of the control. A relation between the concentrations of D-cAMP and the changes in $V^{\prime} \max$ under the influence of thiamylal is shown in Fig. 3. The administration of halothane at concentrations of $7.1 \pm 0.7 \mathrm{mg} \%$ decreased $V^{\prime} \max$ to $73.0 \pm 2.4 \%$ of the control. D-cAMP at concentrations up to $6 \times 10^{-3} \mathrm{M}$ failed to reverse the depression produced by halothane and $V^{\prime} \max$ remained from $73.0 \pm 2.4 \%$ to $89.9 \pm 8.3 \%$ of the control level. A relation between the concentrations of D-cAMP and the changes in $V ' \max$ under the influence of halothane is shown also in Fig. 3. Under the influence of halothane the curve is almost flat, while the thiamylal curve shows a parallel rightward shift from the control.

Statistical analysis of the percent changes in $V^{\prime} \max , \Delta l$ and $F$ with or without the administration of the anesthetics is shown in Table 1. A relation between the concentrations of halothane and the percent changes in V'max produced by 
net shortening $(\Delta l)$ and isometric force $(F)$ produced by $D$-cAMP with or without the influence and halothane

\begin{tabular}{|c|c|c|c|c|c|}
\hline \multicolumn{2}{|c|}{ Thiamylal $3.3 \mathrm{mg} \%$} & \multicolumn{4}{|c|}{ Halothane $7.1 \mathrm{mg} \%$} \\
\hline $3 \times 10^{-3} \mathrm{M}$ & $6 \times 10^{-3} \mathrm{M}$ & 0 & $1 \times 10^{-3} \mathrm{M}$ & $3 \times 10^{-3} \mathrm{M}$ & $6 \times 10^{-3} \mathrm{M}$ \\
\hline $\begin{array}{c}160.6 \\
\pm 24.3 \\
\mathrm{NS} \dagger\end{array}$ & $\begin{array}{l}259.6 \\
\pm 23.5 \\
\pm\end{array}$ & $\begin{array}{c}73.0 \\
\pm 2.4 \\
0.01>p^{*}\end{array}$ & $\begin{array}{r}78.2 \\
\pm 3.0 \\
\text { NSt }\end{array}$ & $\begin{array}{l}87.3 \\
\pm 4.4 \\
\text { NS } †\end{array}$ & $\begin{array}{r}89.9 \\
\pm 8.3 \\
\mathrm{NS} \dagger\end{array}$ \\
\hline $\begin{array}{l}112.0 \\
\pm 8.5 \\
\mathrm{NS}_{\dagger}\end{array}$ & $\begin{array}{l}138.9 \\
\pm 15.8 \\
+ \\
+\end{array}$ & $\begin{array}{c}77.1 \\
\pm 3.6 \\
0.01>p^{*}\end{array}$ & $\begin{array}{r}82.3 \\
\pm 3.2 \\
\mathrm{NS} \dagger\end{array}$ & $\begin{array}{l}86.8 \\
\pm 4.6 \\
\mathrm{NS} \dagger\end{array}$ & $\begin{array}{r}85.4 \\
\pm 7.6 \\
\mathrm{NS}+\end{array}$ \\
\hline $\begin{array}{l}148.9 \\
\pm 18.7 \\
\mathrm{NS}^{\prime}\end{array}$ & $\begin{array}{l}187.4 \\
+\end{array}$ & $\begin{array}{c}62.3 \\
\pm 2.0 \\
0.001>p^{*}\end{array}$ & $\begin{array}{r}65.7 \\
\pm 2.1 \\
\mathrm{NS} \uparrow\end{array}$ & $\begin{array}{l}71.9 \\
\pm 4.8 \\
\mathrm{NS} \dagger\end{array}$ & $\begin{array}{r}74.3 \\
\pm 6.9 \\
\mathrm{NS} \uparrow\end{array}$ \\
\hline
\end{tabular}

thiamylal or halothane.

$\ddagger$ Statistical analysis was not done because of a small number of studies. NS: $p>0.05$.

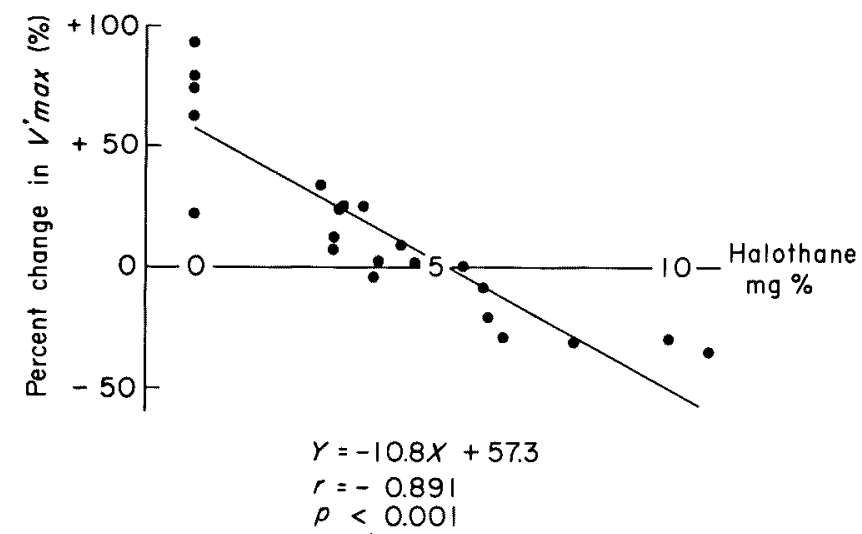

Fig. 4. Changes in the velocity of shortening at $0.4 \mathrm{~g}$ preload ( $V^{\prime}$ max) produced by various concentrations of halothane under the influence of $3 \times 10^{-3} \mathrm{M}$ of $\mathrm{D}$-cAMP. The values are expressed as percent changes compared with those obtained without the administration of halothane and D-cAMP. There is a linear relationship between the concentrations of halothane and the percent changes in $V^{\prime} \max$.

$3 \times 10^{-3} \mathrm{M}$ of D-cAMP is shown in Fig. 4. There was a linear relationship between them, as expressed by the formula $Y=-10.8 X+57.3$, in which $X$ is concentration of halothane in $\mathrm{mg} \%$ and $Y$ is percent change in $V$ 'max compared with the control values. D-cAMP at this concentration counteracted the depression and $V ' \max$ was increased more than the control level when the concentrations of halothane were lower than $5 \mathrm{mg} \%$.

\section{Discusston}

D-cAMP augmented contractile performance of isolated dog heart muscle as manifested by an increase in isometric force $(F)$, net-shortening $(\Delta l)$ and velocity 
of shortening at preload $\left(V^{\prime} \max \right)$. The augmentation of $F$ and $V^{\prime} \max$ was observed at concentrations over $1 \times 10^{-3} \mathrm{M}$ of D-cAMP. These results are comparable to those observed by Skelton et al. (1970) on isolated cat papillary muscle, although the lowest concentration of D-cAMP to produce the augmentation in this study was slightly higher than that in their report.

The slow time course to reach its peak effect was similar to that in their report. The time course of recovery from its effect after washing out the D-cAMP was also slow. This was a sharp contrast to epinephrine which began to produce its positive inotropic effect within $1 \mathrm{~min}$ and reached its peak effect within $3 \mathrm{~min}$. An exact mechanism of difference in the time course of action between D-cAMP and epinephrine is unknown. It has been postulated that a positive inotropic effect of epinephrine is mediated by increased cAMP in the cardiac cells (Robinson et al. 1965), and Drummond and Hemmings (1972) have reported that the exogenous administration of D-cAMP increases the level of cAMP in the cardiac cells. Therefore, the slow rate of D-cAMP passing the cardiac cell membrane or/and the slow rate of D-cAMP being converted to cAMP may be attributable to this difference. Since an opposite effect of cAMP and D-cAMP on glycogen levels was reported in Hela cells (Hilz and Tarnowski 1970), there may be another possibility that the mechanism for augmenting contractile performance differs between cAMP increased by epinephrine and D-cAMP in the cardiac cells.

It is interesting to note that irregular spontaneous contraction of cardiac muscle elicited by D-cAMP at high concentrations was corrected by xylocaine, but it was hardly corrected by propranolol even at high concentrations. A positive inotropic effect of D-cAMP has been reported not to be blocked by propranolol (Skelton et al. 1970). These results suggest that mediation of the action of D-cAMP is independent of the beta-adrenergic receptor.

D-cAMP counteracted the myocardial depression produced by thiamylal or halothane, more easily in the former. When contractile performance of isolated heart muscle was depressed about $25 \%$ by these anesthetic agents, $3 \times 10^{-3} \mathrm{M}$ of D-cAMP definitely counteracted the depression produced by thiamylal, but it failed to reverse the depression produced by halothane. When the concentrations of halothane were lower than $5 \mathrm{mg} \%$, however, $V^{\prime} \max$ was increased more than the control level. Recently Krishna and Paradise (1972) have reported that there is a difference between pentobarbital and halothane in the mode of interference with a glucose utilization system in the human atrial muscle for depressing myocardial contractility. Mayer (1967) has suggested that cAMP plays an important role in glucose metabolism in the myocardium. Therefore, it may be assumed that there is some difference between thiamylal and halothane in the mechanism for depressing contractile performance of the myocardium, consequently resulting in a different response to D-cAMP of the myocardium depressed by these anesthetic agents.

\section{References}

1) Drummond, G.I. \& Hemmings, S.J. (1972) Inotropic and chronotropic effects of 
dibutyryl cyclic AMP. Advanc. cyclic Nucleo. Res., 1, 307-316.

2) Hilz, H. \& Tarnowski, W. (1970) Opposite effects of cyclic AMP and its dibutyryl derivative on glycogen levels in Hela cells. Biochem. biophys. Res. Commun., 40, 973-981.

3) Iwatsuki, N. (1973) The effect of CT 1341, a new steroid anesthetic, on the isolated heart muscle. Tohoku J. exp. Med., 109, 69-75.

4) Krishna, G. \& Paradise, R.R. (1972) Effects of pyruvate on human atrial muscle contractility depressed by methoxyflurane and pentobarbital. Anesthesiology, 36, 364-368.

5) Mayer, S.E. (1967) Effect of epinephrine on carbohydrate metabolism in the heart. In: Factors Influencing Myocardial Contractility, edited by R.D. Tanz, F. Kavaler, \& J. Roberts. Academic Press, New York \& London, pp. 443-455.

6) Posternak, Th., Sutherland, E.W. \& Henion, W.F. (1962) Derivatives of cyclic 3',5'adenosine monophosphate. Biochim. biophys. Acta (Amst.), 65, 558-560.

7) Robinson, G.A., Butcher, R.W., Morgan, H.E. \& Sutherland, E.W. (1965) The effect of epinephrine on adenosine $3^{\prime}, 5^{\prime}$-phosphate levels in the isolated perfused rat heart. Mol. Pharmacol., 1, 168-177.

8) Skelton, C.L., Levey, G.S. \& Epstein, S.E. (1970) Positive inotropic effects of dibutyryl cyclic adenosine $3^{\prime}, \mathbf{5}^{\prime}$-monophosphate. Circulat. Res., 26, 35-43. 